\title{
A reforma trabalhista necessária é possível
}

VALTER U ZZO

U m país que tem muitas leis, não tem leis.

Balzac

\section{Introdução}

A PRIMEIRA QUESTÃo que se coloca é a de que a reforma trabalhista, se realizada como está ou até mesmo uma mais radical e profunda, ainda assim não conduzirá à nada, posto que o sistema trabalhista é apenas parte de um sistema geral - que funciona cada vez mais de forma deficiente e precária. A reforma trabalhista, para ter eficácia, precisa ser operada em três níveis, quais sejam, a reforma do Direito do Trabalho, a reforma da J ustiça do Trabalho e a reforma do Poder J udiciário em geral. Trata-se de uma tarefa gigantesca, somente possível em uma sociedade em que haja uma alteração na base da relação das classes e setores sociais, com a classe dominante cedendo a um realinhamento geral, a implicar, também, uma grande desconcentração da riqueza e melhor distribuição de renda. $\mathrm{N}$ ão estou me referindo a uma revolução social ortodoxa ou clássica, que seria, certamente, a solução mais completa, mas sim a alterações do poder, ainda que não se ultrapassassem os limites atuais da chamada economia de mercado, capitalista.

A realidade do país é muito dura: cinqüenta milhões de brasileiros vivem abaixo da linha da pobreza e, destes, 22 milhões estão na indigência absoluta. O u seja, estão à margem do país formal, o direito, a lei, a justiça não se Ihes chega, a não ser para punir. Vivem na zona absoluta do não-direito, e, para existir - já que não podem pagar a comida, a casa, a luz, o aluguel, a água - acabam, direta ou indiretamente, infringindo a legalidade das regras do país formal. T êm de violar a legalidade para continuar existindo! A esses, a prioridade é a reforma do Direito do Trabalho, que poderá influir na obtenção de um emprego, que significa salário e acesso ao Estado formal.

Esse primeiro eixo - a reforma do Direito do Trabalho - será ou não um fator de geração de emprego? É claro que, por si só, não, já que esse problema só o desenvolvimento econômico poderá resolver (enganosa e cavilosamente existe a pregação de que as normas trabal histas são as culpadas pelo desemprego), mas, evidentemente, poderá dar alguma contribuição significativa nessa direção. Portanto, a reforma do D ireito do Trabalho, sob o ponto de vista de fator de geração de emprego, surge como dependente do desenvolvimento econômico. H á uma inter-relação entre os dois, uma reforma do Direito do Trabalho poderá ter 
alguma significância, mas não terá o papel essencial na geração de emprego. Esse ponto é muito importante, posto que tem servido como fator diversionista na real discussão sobre as cau sas desta semiparal isia da economia dos últimos vinte anos. O embuste é facilmente desmascarável: crescemos nas décadas de 1940 a 1970 com esse mesmo D ireito do Trabal ho, sem contar que, hoje em dia, estimase que $60 \%$ da força de trabalho do país esteja na informalidade, ou seja, fora de quaisquer regras trabalhistas.

\section{D emocratização da J ustiça e J ustiça do T rabalho}

A Justiça do Trabalho, mais ainda, o D ireito do Trabalho, movem-se em torno de um instituto chamado contrato detrabalho. Este é o centro aglutinador, o denominador comum, para onde acorrem os três grandes vetores do mundo jurídico do trabalho - o direito sindical, o direito coletivo e o direito individual do trabalho, sendo aJ ustiça do Trabalho o grande palco de solução das desavenças. M as, há uma peculiaridade interessante: a Justiça do Trabal ho tem uma relação dependente das alterações que vierem a ser feitas no direito sindical, nas normas coletivas e no direito individual. Por exemplo, o novo Código Civil, cuja vigência é recente, ou o Código de Processo Civil de 1973, não exigiram uma pronta reforma da justiça cível; o mesmo se deu na esfera criminal, eis que novos códigos Penais ou de Processo Penal jamais implicaram na necessidade iminente de reforma da J ustiça Criminal. No campo do D ireito do Trabalho, no entanto, a questão é diferente, há uma inter-relação permanente e constante entre as normas de direito, e aJ ustiça Trabal hista. U ma mudança profunda nos direitos coletivos e individuais do trabalho e na organização sindical produzem a necessidade inadiável de alteração da Justiça do Trabalho, posto que se complementam e se permeiam dialeticamente. $\mathrm{N}$ ão só isso, no entanto. As mudanças na Justiça do Trabalho também estão na dependência das reformas a serem feitas no Poder Judiciário geral, até porque é parte do todo, e deve obedecer, em linhas gerais, os mesmos princípios administrativos e jurisdicionais.

\section{0 rigens da crise}

A crise da Justiça do Trabalho decorre de um processo de acumulação de erros do Poder Público, desde o surgimento da I nstituição, que foi criada, certamente, para o Estado controlar o movimento sindical, administrar as crescentes crises trabalhistas e conciliar uma aguda luta de classes que se prenunciava. E m 1932 existiam as J untas de Conciliação e J ulgamento, instituídas por um decreto legislativo, tribunais administrativos cujas decisões valiam apenas como títulos a serem executados na J ustiça C omum. No curso dos debates da Constituição de 1934, idealiza-se a J ustiça do Trabalho, que, embora tenha sido objeto de discussões nas comissões, não consta do texto final. A C onstituição de 1937 institui a J ustiça do Trabalho, que é criada e instalada em 10 de maio de 1941, através de um D ecreto do governo de Getúlio Vargas. O Tribunal Superior do Trabalho, criado em 1946, definiu a estrutura desse setor da J ustiça (que é muito simples) 
e que lembra a expressão geométrica de uma pirâmide: na 1ª instância (a base da pirâmide) de Varas (as antigas J untas de Conciliação e Julgamento); a 2 a instância (o meio), de Tribunais Regionais do Trabalho, atualmente à razão de um TRT por Estado Federativo (com exceção de São Paulo, onde há dois TRTs, um na Capital, cuja jurisdição compreende a grande São Paulo e Baixada Santista, e outro em Campinas, que compreende todo o interior do Estado); e, por fim, a Instância Superior, o Tribunal Superior do Trabalho. H oje, toda a Justiça do Trabalho contém 1.109 Varas em 4.728 municípios, e são distribuídos, atualmente, cerca de dois milhões de processos por ano. D e cada cem processos, 45 são conciliados, vinte são arquivados ou não recorrem, trinta chegam ao TRT, cinco ao TST. Tamanha carga de processos é despejada sobre uma estrutura pequena e inadequada - que pouco se alterou desde sua criação. As Varas foram dimensionadas para receber setecentos processos por ano, recebem mais de três mil dados de São Paulo, C apital. A capacidade poderia ser de 1.200 processos em andamento por Vara, mas o número varia de cinco a doze mil; cada Vara haveria de ter dois juízes, um titular outro substituto, auxiliando: tem apenas um; o número de funcionários estabelecido foi de catorze por Vara, mas a média atual é de só sete. Bem, vistos esses números, a primeira e óbvia conclusão a que se chega é que a falta de pessoal, cumulada com uma imensa sobrecarga de processos, é a causa primeira das dificuldades de funcionamento da J ustiça do Trabalho. $N$ ão há ustiça que possa funcionar sem magistrados e funcionários suficientes. Essa falta de recursos humanos é complementada por freqüente carência de recurso materiais. Tempos existiram - e não foram poucos e nem de curta duração - que não havia papel, fitas, máquinas, enfim, um mínimo de material de escritório para ajurisdição funcionar, ainda que precariamente. As instal ações, tomada a J ustiça do Trabalho no Brasil todo, são adaptadas, os fóruns pequenos e inadequados, enfim, as instalações materiais são, em geral, também precárias.

\section{$\mathbf{N}$ ão investir por razões políticas, não investir por falta de recursos e não investir por interesse}

Tudo isso é agravado por uma contradição que o modelo neoliberal tornou insuperável: é que, de um lado, a jurisdição se amplia - aqui e no mundo todo -, pois 0 acesso à justiça é um direito da cidadania que tende a se tornar cada vez mais efetivo, as pessoas se esclarecem da titulariedade de seus direitos e a própria divisão do trabalho gera situações novas, novas profissões, novas relações jurídicas e novos direitos (que podem ou não ser violados). De outro lado, o Estado neoliberal pretende ser cada vez mais pequeno e restrito, um aparel ho mais compacto, a viver com menos recursos e, portanto, a investir menos. $\mathrm{No}$ caso do Brasil, essa tendência foi agravada por uma crise financeira que dura décadas. Assim, vale dizer, a tendência ideológica do Estado, que era não investir no Judiciário, casou-se com sua política econômica de também não investir por alegada falta de 
recursos financeiros, não investir por decisão política e não investir por não ter dinheiro. A atuar sobre esse contexto há ainda outra vertente: não existia mais interesse político na aplicação de recursos no Poder J udiciário, já que era o único a, por vezes, não se submeter ao controle do Poder Executivo e demonstrar alguma independência. 0 Executivo, ao longo dosanos, usurpou as competências institucionais do legislativo, reduzindo-o a mero poder de fiscalização política (um recente estudo sobre a proliferação de leis no país, demonstra que apenas $6 \%$ da legislação se origina do legislativo!). Controlando as verbas orçamentárias, o executivo traz o J udiciário a rédeas curtas, obrigando as direções dos Tribunais à um périplo pelos escaninhos dos $\mathrm{M}$ inistérios, a rogar pela liberação de verbas. Essa forma cavilosa de atentar contra o outro Poder, procurando tisnar sua competência, criando vínculos de dependência e gratidão, acaba por deixar o J udiciário em situação ainda mais difícil. Como resultante, o Judiciário passou a viver uma situação de permanente penúria, com má remuneração dos juízes e do funcionalismo ea falta de recursos materiais. 0 resultado disso é: um J udiciário mergulhado em uma crise sistêmica, dependente, presa dócil de uma ideologia neoliberal, de um determinismo econômico fatal e de um interesse político adverso.

\section{O utros complicadores}

Esse fator não é o único, mas o principal do agravamento da crise do Judiciário. $\mathrm{N}$ a J ustiça do Trabalho, somam-se outros complicado res específicos, também importantes: a situação econômica agrava as relações de trabalho, provocando intensa rotatividade da mão-de-obra, excessivo número de empregados sem registro e contratos simulados (terceirização, cooperativas etc.).

O quadro é muito difícil: uma estrutura arcaica, com falta de recursos humanos e materiais, tendo que resolver anualmente cerca de dois milhões de processos, não tem como funcionar a contento. A demora dos feitos trabal histas desnatura o sentido moralizador e pedagógico do processo, elimina todos os sentimentos subjetivos das partes e os remete para outra realidade, que nada tem a ver com aquela que originou o conflito. São dois estranhos, o clima de litigiosidade esmaeceu no tempo, o reclamante de agora está a receber o direito de quem não o conhece, e como as pessoas jurídicas desse país tem vida curta, provavelmente um estranho sucessor Ihe dará o que um outro se lhe negou. D estrói-se, assim, o componente subjetivo fundamental do processo, que é o reconhecimento do sentimento justo, a reparação da injustiça sofrida, a satisfação subjetiva da titulariedade do direito, a pedagogia do processo e da justiça.

\section{M udanças estruturais na cúpula do poder}

$M$ as, se tivesse os recursos de que necessita, a J ustiça do Trabalho poderia cumprir com a desejável eficácia o seu papel? É claro que, com a atual estrutura, não seria possível. Para tanto, seria necessária uma série de propostas, sejam de fundo ou para a qual de forma são realizadas. N o nosso entendimento, al gumas 
modificações na organização judiciária a começar por drástica redução da competência do Tribunal Superior do Trabalho são prioridade, ou mesmo sua extinção, uma vez que perdeu sua destinação original. Este referido tribunal foi criado como tribunal extraordinário, para uniformizar a jurisprudência, a qual deveria ser seguida e aplicada pelas instâncias inferiores. $\mathrm{N}$ o entanto, tornou-se uma verdadeira terceira instância, cuja preocupação maior, nosúltimos dez anos, foi a de tentar evitar a avalanche descomunal de processos que lhe assoberba. $\mathrm{N}$ ão tem capacidade física de bem julgar quinze mil processos por ano, e lá chegam mais de cem mil! Tornou-se, assim, involuntariamente, fator de imensa letargia na tramitação do processo. Por outro lado, dada as peculiaridades de cada região, as relações de emprego se diferenciam muito segundo a realidade concreta local. $D$ aí porque um único Tribunal, a aplicar as mesmas regras jurídicas em duas relações de emprego informadas por realidades sociais e econômicas completamente diferentes, significa uma padronização de situações infinitamente desiguais, vale dizer, as relações de trabalho nos Estados de São Paulo e do Amazonas são diferentes, não se Ihes pode dar tratamento igual. Portanto, a regionalização da Justiça do Trabalho, com maiores poderes aos Tribunais Regionais, que vivem a realidade viva de suas regiões, permitirá à J ustiça uma prestação mais próxima, e por isso mesmo, mais acertada. Ainda com relação aos Tribunais, é imperioso que sofram um processo de maior democratização, com a eleição direta de seus membros pelos integrantes da corporação, ainda que J uizes de 1a Instância. Assim osjuízes concorreriam aos Tribunais Regionais, preenchidas certas condições, em eleições diretas pelos magistrados da 1ạ I nstância. O s juízes do TRTs elegeriam, também diretamente, os do TST, e assim sucessivamente. 0 s representantes pelo 50 Constitucional advindos da advocacia e do ministério público seriam eleitos diretamente pelos seus pares. Tal sistema evitaria a dependência política da escolha, posto que, atualmente, os candidatos devem realizar um verdadeiro calvário por gabinetes de políticos para, afinal, serem indicados para compor os Tribunais Superiores (TST, STJ e TSM ) e o próprio Supremo Tribunal Federal. Também a criação de um Conselho Nacional de J ustiça, a retraçar uma política nacional para todo o sistema judiciário, com poderes administrativos para, junto com as corregedorias, evitar desmandos e práticas corporativas, poderia dar uma boa contribuição.

\section{M udanças no D ireito individual}

No campo do direito individual do trabal ho é oportuno destacar que, ao contrário do que é profusamente difundido por setores comprometidos com a ideologia do "mercado", nossa legislação já atingiu, em comparação com o direito de outros países, um alto grau de "flexibilização": é permitida a utilização de empresas de trabalho temporário (Lei 6.019/74), ampla liberdade patronal para despedir empregados (L eis 5107/ 66 e 8036/ 90), quebra do princípio da irredutibilidade salarial por acordo ou convenção coletiva (art. 70 , VI, da C onstituição), flexibilização das jornadas de trabalho, com compensação e banco de 
horas (art. 70 da Constituição e art. 60 da Lei 9.601/ 98), ampliação da jornada de seis horas dos turnos ininterruptos art. 7ํ , XIV, Constituição ), contrato de trabalho provisório com ampla redução de direitos (L ei 9.601/ 98), trabalho a tempo parcial (M P 1709/98), terceirização em determinadas hipóteses (E nunciado 331 do TST), redução das hipóteses do salário utilidade (L ei 10.243/ 2001), suspensão de dois a cinco meses do contrato de trabalho M P 2.164/ 01) e assim por diante. Todas essas alterações visaram a baratear o custo da mão-de-obra e implicaram em redução de direitos trabal histas, o que, a nosso ver, também partiu de bases falsas: temos uma altíssima rotatividade de mão-de-obra, enquanto na Europa, 41,5\%dos trabal hadores conservam o emprego por mais de dez anos! Estudos da O IT revelam que tais trabalhadores aumentam a produtividade média em 0,16\% por ano, até o sétimo ano, quando então se estabiliza. 0 u seja, sem sacrificar os direitos trabal histas, a produtividade cresceu na Europa. N ão é, portanto, com essa simplória proposta de redução de direitos trabalhistas que se aumenta a produtividade. A baixa produtividade, todos sabemos, decorre de uma série de fatores, tais como falta de investimentos em recursos humanos e materiais, rotatividade de mão-de-obra, taxas de freqüência, acidentes de trabaIho e doenças profissionais etc.

0 " $x$ " da questão reside nos elevados encargos que incidem sobre os salários e, com exceção dos depósitos do FGTS, tudo o mais não diz respeito ao trabalho em si e nem à relação de emprego. O neram os salários as contribuições relativas à assistência social, ao aprendizado profissional, à pequena e microempresa, à reforma agrária, à educação, e outras. A deformação é tão grande que atingiu a própria previdência social, já que o desconto nos salários é grande, mas a previdência não se limita só ao empregado, ela é universal, ou seja, o amplo universo da previdência é bancado pelo trabalho assalariado, só ele.

Portanto, no campo do direito individual do trabalho, o primeiro pressuposto de uma reforma trabal hista seria o de desonerar o salário desses penduricalhos que não dizem respeito à relação de emprego. H averia um "barateamento" do custo da mão-de-obra, sem quaisquer prejuízos sal ariais. O utra medida importante seria o de limitar o trabalho extraordinário, só o permitindo em casos de força maior ou necessidade imperiosa, com o que se abririam mais postos de trabalho, os acidentes de trabal ho se reduziriam, as doenças profissionais etc. Q uanto à flexibilização do trabal ho, as hipóteses deveriam ser bem definidas, sempre sob a tutela sindical. A liberação do FGT S em qualquer tipo de rescisão contratual, a exceção das dispensas por falta grave, produziria um grande ingresso de recursos no mercado de consumo. Tais recursos, hoje, ficam em mãos do Governo e são remunerados por taxas de juros muito inferiores às do mercado, o que representa um injustificável ganho adicional pelo sistema bancário e pelo Governo. A reformulação do tratamento legal em relação ao trabalho em condições de periculosidade ou insalubridade, visando a eliminá-los ou a reduzi-los a proporções mínimas é fundamental. D o mesmo modo o é a regulamentação do exercício de 
profissões por meio de convenções coletivas, observando-se certas normas legais, e a reformulação do direito penal do trabalho, com o objetivo de evitar as fraudes, violências e desmandos cometidos contra os trabalhadores.

\section{D ireito coletivo e sindical}

Esperava-se que, com a instituição do Fórum $\mathrm{N}$ acional do Trabalho, surgisse uma proposta consensual de ampla e profunda reformulação da organização sindical, tornando-a mais representativa e fortalecida. A proposta, no entanto, está muito longe disso: além de confusa em algumas questões essenciais, é mal sistematizada e contraditória, chega mesmo a propor a volta a um passado atrasado. A interferência estatal nos sindicatos retorna em grande estilo, já que caberá M inistério do Trabalho conceder ou não os pedidos de registro; propõe-se também o retorno ao sistema antigo do quadro de atividades e profissões, cabendo ao Estado mapear a economia e definir se pode ou não constituir sindicatos para representar grupos profissionais; os sindicatos só existirão após a autorização estatal, ou seja, a famigerada carta sindical; a unicidade sindical proposta é estranha e confusa: somente poderá existir sindicato por ramo de atividade delineada pelo Estado, mas os sindicatos preexistentes à reforma, dependendo do nível de sindicalização, poderão obter exclusividade de representação, e os exclusivos poderão sofrer concorrência dos sindicatos orgânicos, que as centrais poderão criar como "representatividade derivada". Em suma, a proposta instaura a representação única por território previamente delimitado pelo Estado, sob autorização do Estado, e, exclusivamente, por ramo deatividade, o que implica na dissolução dos atuais sindicatos por categoria. 0 poder normativo da J ustiça do Trabalho, embora a proposta o proclame como extinto, não o será: a JT não poderá aplicar o poder normativo apenas em caso de greve. No mais, passados noventa dias, a Justiça julgará o conflito, substituindo-se a expressão "poder normativo" por "arbitramento público". N a questão da greve, a proposta é de que o Poder Público não poderá julgá-la (o que, por sinal, viola a cláusula pétrea da C arta M agna de que nenhuma suposta lesão de direito poderá ser excluída da apreciação pelo Poder Judiciário). As partes não mais poderão esperar pelo julgamento da Justiça, de uma situação de impasse, vale dizer, uma das partes terá de ceder. Está claro que nas circunstâncias atuais, como uma lei dessas, não haverá greves. A representação por empresa e o direito à contratação coletiva para os empregados públicos continuarão como estão, ou seja, são mantidas sem regulamentação, tornando-se, assim, "direitos inoperantes". Pressupõe a existência de direitos "negociáveis" e de "inegociáveis" e, a se levar em conta o que dizem os ministros do G overno e o próprio Presidente da República, inegociáveis serão só as férias, tudo em clara adesão ao projeto de flexibilização do Banco M undial. Enfim, o projeto deixa muito a desejar.

E no nosso entender, uma reforma sindical que tenha por objetivo fortalecer a atividade sindical terá, necessariamente, que se balizar nos seguintes pressupostos: 
legalização das centrais sindicais, a fim de que se possam firmar acordos e convenções coletivas e se desenvolver plena atividade sindical; normas de proteção contra atos anti-sindicais, de tal sorte a permitir-se a livre associação e o desenvolvimento de atividades necessárias aos fins sindicais, sem interferências de práticas ilegais, quando não criminosas; um conjunto de normas de incentivo à negociação coletiva, a estimulá-la em direção à negociações de boa-fé; definição, pela lei, de um conjunto mínimo de direitos inegociáveis, responsabilizando-se diretamente a entidade e 0 dirigente sindical se transacionados prejudicialmente quaisquer um desses direitos; direito de informação sobre à empresa, desde que relacionados aos interesses objetivos da negociação; acesso pleno a empresa para fins de organização sindical, desde queem horário que não cause, direta ou indiretamente, qualquer prejuízo no processo produtivo; extinção gradativa de todas as contribuições - sindical, confederativa e assistencial - , a não ser a aquela vinculada à negociação coletiva, a ser paga por todos aqueles beneficiados pela convenção coletiva, independentemente da filiação, e em valor moderado; extinção da possibilidade de se conceder efeito suspensivo (ou outra medida idêntica) em dissídio coletivo (os dissídios coletivos foram desestruturados em razão das absurdas concessões pelo TST dos efeitos suspensivos, deixando categorias inteiras sem convenções coletivas, no aguardo de um julgamento por anos e anos); ultratividade das normas coletivas (enquanto não sobrevir nova convenção, valerá a anterior); normas que obriguem a negociação prévia no caso de demissão em massa; e direito de greve, inclusive para os servidores públicos, desde que protegidos os direitos essenciais da população. U ma legislação dotada com tais princípios por certo representaria o fortalecimento das atividades sindicais, evitando os abusos que fogem aos reais interesses das classes em litígio.

\section{R eforma do processo trabalhista}

A completar esse conjunto de reformas, o processo do trabalho deveria sofrer algumas alterações. 0 chamado processo de conhecimento, na 1a instância, traz os mais modernos conceitos processuais e não necessita de alteração. Com recursos e pessoal suficientes, os feitos trabalhistas em 1 a instância não durariam mais do que trinta dias. Já o sistema recursal, ainda na fase de conhecimento, poderia ser reduzido e limitado, mantendo-se fundamentalmente o recurso ordinário, embargos de declaração e agravo de instrumento, na forma atual. Já o recurso de revista (se não extinto o TST), somente poderia ser recebido e conhecido se violada lei federal ou a Constituição. 0 agravo de instrumento, contra decisões de indeferimento da subida da revista, só poderia ter seguimento se garantido o Juízo, com depósito de valor arbitrado ou oferecimento de penhora de bens livres e desembaraçados de quaisquer ônus. Também muito contribuiria para 0 desentulho, até porque não se justifica a abolição dos privilégios das entidades de direito público, inclusive com limitações ao recurso ex offício. Por fim, majoração do valor da multa por litigância de má fé. 
A execução, sabidamente, é o "calcanhar de Aquiles" do processo trabal hista. Se forem adotadas todas as medidas e alterações contidas nas despretensiosas sugestões dessas linhas, ainda assim, tudo será inútil, se não vier a ser alterada a execução. E teria de ser, a nosso ver, a partir do princípio teórico (=ideológico) que norteia o processo de execução trabal hista. Como sabido, é ele comandado pelo princípio da execução menos onerosa, que vigora no processo civil. O ra, no cível o devedor, geralmente, é o pólo economicamente mais frágil do processo: é aquele que não pagou o empréstimo, ou que se atrasou nas prestações do imóvel adquirido, ou que não conseguiu cumprir com os aluguéis, e assim por diante. Q uem o executa, comumente, está em situação de superioridade econômica. Assim, o princípio da "execução menos onerosa" tem por objetivo não agravar ainda mais a situação do executado, com dispêndios que só vão tornar a dívida mais difícil de ser quitada. Asnormais processuais, portanto, são feitas no sentido de que ele possa utilizar-se de uma série de expedientes para reduzir o débito e torná-lo acessível à paga. Já na J ustiça do Trabalho é o inverso: o devedor, se lá no cível é o "fraco", aqui é o "forte", ou seja, aqui o empregado é o credor, e o devedor, a empresa, o banco, o Estado, a opor toda espécie de resistência à quitação final do débito. A execução, assim, torna-se um calvário, são expedientes os mais diversos, tudo no sentido de retardar a quitação final do processo, até porque o valor da execução, se aplicado ao mercado, rende mais dos que os juros e correção monetária do débito trabalhista. Existem dois fatos que a agravar ainda mais a execução trabalhista e torná-la mais morosa: um é a questão da penhora, já que, hoje em dia, os bens são difíceis de serem penhorados, seja porque pertencem a terceiros (leasing), seja porque não mais despertam interesses em praças e leilões (máquinas de escrever, móveis de escritórios, computadores, telefones, automóveis), uns porque estão em desuso (máquinas e móveis), outros porque não mais têm valor econômico (telefones), outros porque "envel heceram" no longo curso da execução (computadores), outros porque os gravames, multas (caso dos automóveis) chegam a quase superar o valor da penhora. O u seja, sobra a penhora em conta bancária, que a lentidão da execução faz permitir que o titular, sagazmente, passe-a em nome de outrem. 0 segundo é a questão da execução contra a Fazenda Pública, que, após Ionga tramitação do processo e da execução, é expedido um precatório, que leva muitos anos para ser quitado, quando o é.

Para reverter 0 atual quadro, há que se alterar o princípio teórico que 0 informa, ou seja, de "execução menos gravosa", para o princípio da "execução mais rápida e eficiente". Assim, os devedores, porque juridicamente mais capazes do que os credores, teriam, a cada recurso ou manobra protelatória da execução, um agravamento do débito, de tal sorte a desestimular a procrastinação; redução dos recursos, suprimindo-se os embargos ou agravo de petição; a criação de um Fundo de Execuções T rabalhistas para garantir salários e indenizações até determinado limite, composta a sua receita de multas e de infrações trabalhis- 
tas - devidas ao Poder Público, parte das custas, parte dos 10\%do FGTS, o I N SS e o IR arrecadados pela Justiça do Trabalho, multas previstas nas convenções coletivas etc. Também a aplicação de multa pelo Juiz da Execução em caso de descumprimento da sentença, os ônus que gravam os bens penhorados serem de responsabilidade do devedor - e não acompanharem os bens, e outras medidas pragmáticas, como a existência de um contador para cada Vara Trabalhista, um depositário judicial para guarda de bens penhorados, entre outros.

Q uanto aos precatórios, há que se ter uma lei específica tratando desse tipo de execução, permitindo-se a penhora em alguns bens da Fazenda Pública (títulos de valores etc.), bem como facultando-se a cessão desses créditos para quitar dívidas fiscais com o poder público (já há precedentes na jurisprudência).

Em linhas gerais, são essas as sugestões que me ocorrem para que o processo trabal hista possa ser um instrumento a serviço do jurisdicionado. É claro que tudo isso é muito difícil de ser implementado, os interesses da elite dominante são superiores e poderosos, e há, também, toda uma cultura jurídica atrasada a ser superada, e o movimento sindical experimenta uma época de descenso que parece nunca chegar ao fundo do poço. A classe trabalhadora, perplexa com sua situação de desemprego e desesperança, espera que o governo eleito resolva sua situação, que os investimentos internacionais produzam um espetáculo de crescimento, que o superávit fiscal mantenha a inflação em baixa e que o país venha a crescer que surgiam políticas públicas para amenizar sua situação de miséria, e que os discursos sejam levados à prática. Tudo isso estoicamente, até que um dia, que talvez não esteja tão longe quanto se imagina, se canse de esperar...

Valter U zzo é advogado e professor. Foi presidente do Sindicato dos Advogados do Estado de São Paulo e ex-Secretário Geral da OAB/ SP.

Texto recebido e aceito para publicação em 27 de junho de 2004. 